\title{
Buruli Ulcer: a Review of the Current Knowledge
}

\author{
Rie R. Yotsu ${ }^{1,2,3} \cdot$ Koichi Suzuki $^{4} \cdot$ Rachel E. Simmonds $^{5} \cdot$ Roger Bedimo $^{6,7} \cdot$ Anthony Ablordey $^{8}$. \\ Dorothy Yeboah-Manu ${ }^{8} \cdot$ Richard Phillips $^{9} \cdot$ Kingsley Asiedu ${ }^{10}$
}

Published online: 28 September 2018

(C) The Author(s) 2018

\begin{abstract}
Purpose of the Review Buruli ulcer (BU) is a necrotizing and disabling cutaneous disease caused by Mycobacterium ulcerans, one of the skin-related neglected tropical diseases (skin NTDs). This article aims to review the current knowledge of this disease and challenges ahead.

Recent Findings Around 60,000 cases of BU have been reported from over 33 countries between 2002 and 2017. Encouraging findings for development of point-of-care tests for BU are being made, and its treatment is currently in the transition period from rifampicin plus streptomycin (injection) to all-oral regimen. A major recent advance in our understanding of its pathogenesis has been agreement on the mechanism of action of the major virulence toxin mycolactone in host cells, targeting the Sec61 translocon during a major step in protein biogenesis.

Summary BU is distributed mainly in West Africa, but cases are also found in other parts of the world. We may be underestimating its true disease burden, due to the limited awareness of this disease. More awareness and more understanding of BU will surely contribute in enhancing our fight against this skin NTD.
\end{abstract}

Keywords Buruli ulcer $\cdot$ Mycobacterium ulcerans $\cdot$ Mycolactone $\cdot$ Non-tuberculous mycobacterial disease $\cdot$ Skin neglected tropical diseases $\cdot$ Skin NTDs

\section{Introduction}

Buruli ulcer (BU) is a necrotizing cutaneous disease caused by the bacterium, Mycobacterium (M.) ulcerans, which is classified by the World Health Organization (WHO) as one of the skinrelated neglected tropical diseases (skin NTDs) $[1 \bullet, 2]$. Clinically,

This article is part of the Topical Collection on Cutaneous Mycobacterial Diseases of the Skin and Soft Tissues

Rie R. Yotsu

yotsurie@ hotmail.com

1 School of Tropical Medicine and Global Health, Nagasaki University, Nagasaki, Japan

2 Department of Dermatology, National Center for Global Health and Medicine, Tokyo, Japan

3 Department of Dermatology, National Suruga Sanatorium, Shizuoka, Japan

4 Department of Clinical Laboratory Science, Faculty of Medical Technology, Teikyo University, Tokyo, Japan

5 Department of Microbial Sciences, School of Bioscience and Medicine, University of Surrey, Surrey, UK
BU starts with a papule, nodule, plaque, or edematous lesion that eventually progress to extensive skin ulceration (Fig. 1). Remarkably given the extent of tissue loss, the lesion is usually painless or only with limited pain. Unlike other mycobacterial diseases, a unique aspect of $\mathrm{BU}$ is that the pathology of the disease can be ascribed to its lipid-like and diffusible exotoxin,

6 Department of Medicine, VA North Texas Healthcare System, Dallas, TX, USA

7 Division of Infectious Diseases, University of Texas Dallas Southwestern, Dallas, TX, USA

8 Department of Bacteriology, Noguchi Memorial Institute for Medical Research, University of Ghana, Legon, Ghana

9 Kumansi Centre for Collaborative Research in Tropical Medicine, Kwame Nkrumah University of Science and Technology, Kumasi, Ghana

10 Department of Control of Neglected Tropical Diseases, World Health Organization, Geneva, Switzerland 


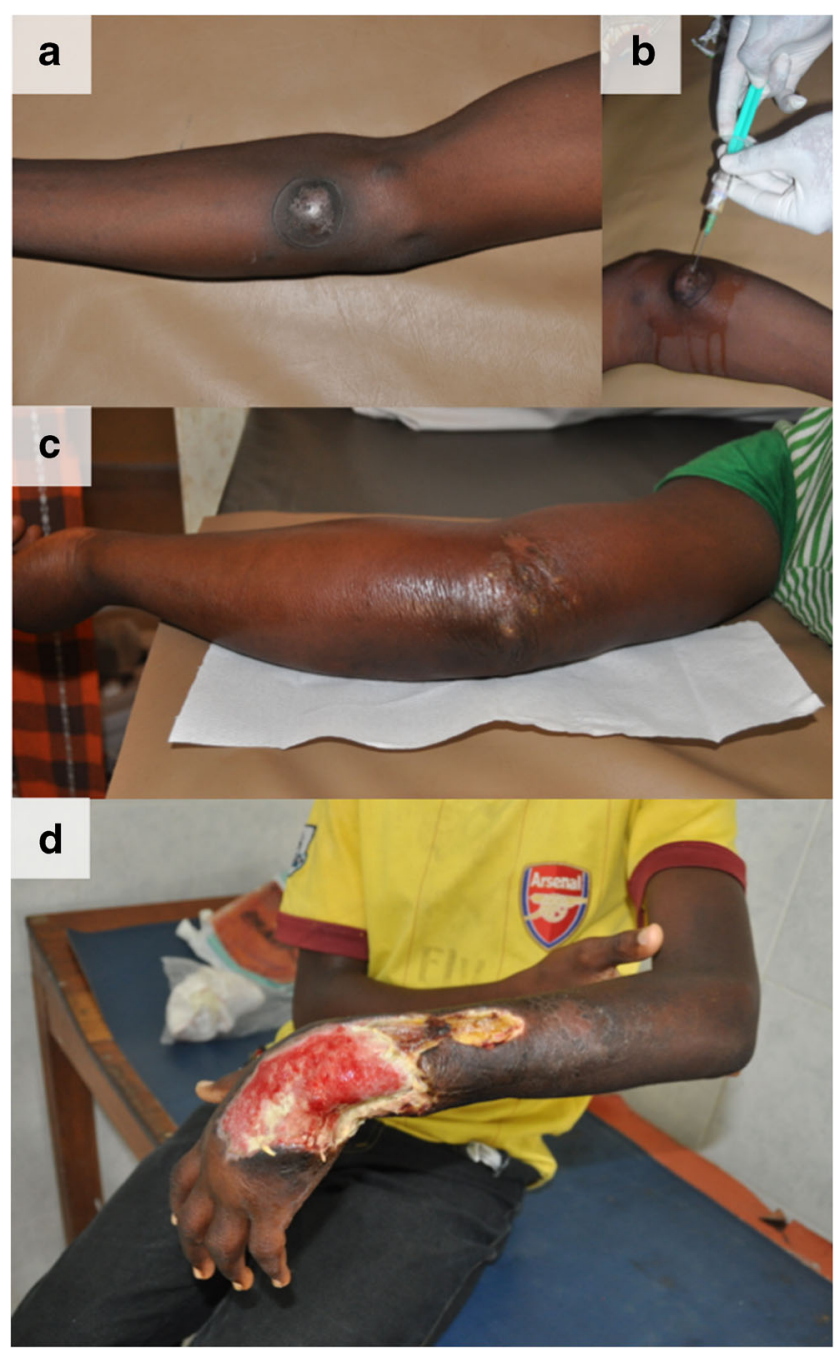

Fig. 1 Clinical presentation of Buruli ulcer, a nodule stage. b Pale yellowish pus was aspirated by the fine needle aspiration and sent for PCR confirmation. c Edematous stage. This stage is usually associated with redness, swelling, as well as considerable pain. d Typical ulcer observed in Buruli ulcer. Deep, undermining of the wound edges, with thick necrotic tissue affecting the limb and the joint of a child

mycolactone, and not the organism itself. The majority of cases are seen in West Africa and in other tropical countries; however, the disease has also been reported in countries with subtropical and temperate climates. Imported cases have been reported from non-endemic countries, and this calls for more awareness among healthcare practitioners globally. While antibiotic therapy is available and usually effective, patients with severe forms or delayed therapy could be left with life-long disabilities and deformities. Early detection and treatment is currently the only measure to prevent deleterious consequences, especially in a disease that often affects children. Yet, several unanswered questions remain which would be key to controlling this disease, including identification of the route(s) of transmission and some aspects of its pathogenesis. In this article, we review updated knowledge on epidemiology, clinical presentation, and management of this disease and future challenges.

\section{Update on Epidemiology}

BU was first described in Australia by MacCallum in 1948 [3, 4]. Currently, over 33 countries worldwide - including West Africa, Central and South America, and the Western Pacificreport cases of BU. The West African countries of Côte d'Ivoire, Ghana, and Benin are the top three endemic countries accounting for approximately $73 \%$ of the total BU cases reported globally [5] (Table 1). The highest numbers of cases reported from these three countries were 2679 cases in 2009, 1157 cases in 2004, and 1203 cases in 2007, respectively. A decrease in reported cases from these countries is however observed in recent years, for unclear reasons, including possible under-diagnosis or under-reporting of cases. Nigeria, on the other hand, started to report cases of BU since 2006 with gradual increase in their reported cases [5], which may be an indication of wider distribution of the disease in countries in this region. In Africa, about $48 \%$ of cases occur in children aged under 15 years [6], the most vulnerable population, which increases the public health importance in tackling this disease.

Interestingly, unlike many other tropical diseases, BU is also seen in countries outside the tropical climate zone, including Australia and Japan. In Australia, cases are especially concentrated in the bay area of the Victoria region, in the south-eastern part of the country [7]. The situation in Australia seems to be evolving, with sharp increase in number of cases from a previous average of 100 to 186 cases in 2016 and 283 cases in 2017 [5]. In Japan, a total of 66 cases since 1981 have been reported to date, with no specific geographical distribution [8]. Several cases are reported by the same medical institutions, suggesting that the awareness of healthcare practitioners is the key for the diagnosis.

There have been sporadic case reports of imported cases from endemic regions, for example, from Australia to the USA and from Angola to Germany [9, 10]. A case diagnosed in the Netherlands, with polymerase chain reaction (PCR) investigation, revealed the causative bacteria to be the same strain as the cases in Japan-M. ulcerans subsp. shinshuense [11]. The patient had a travel history to the Shan Dong Province of China where the latitude is above $30^{\circ} \mathrm{N}$, and where there have been no previously described BU cases. BU occurrence at such high latitude is rare and had only been reported in Japan, suggesting that M. ulcerans subsp. shinshuense is more adapted to environments at higher latitudes than strains of the classical M. ulcerans lineage in tropical and subtropical climate zones [11]. With accelerating globalization and with existence of case reports from new sites, awareness of this disease among healthcare practitioners is needed more widely to enable diagnosis and appropriate treatment, and also to understand its true distribution. 


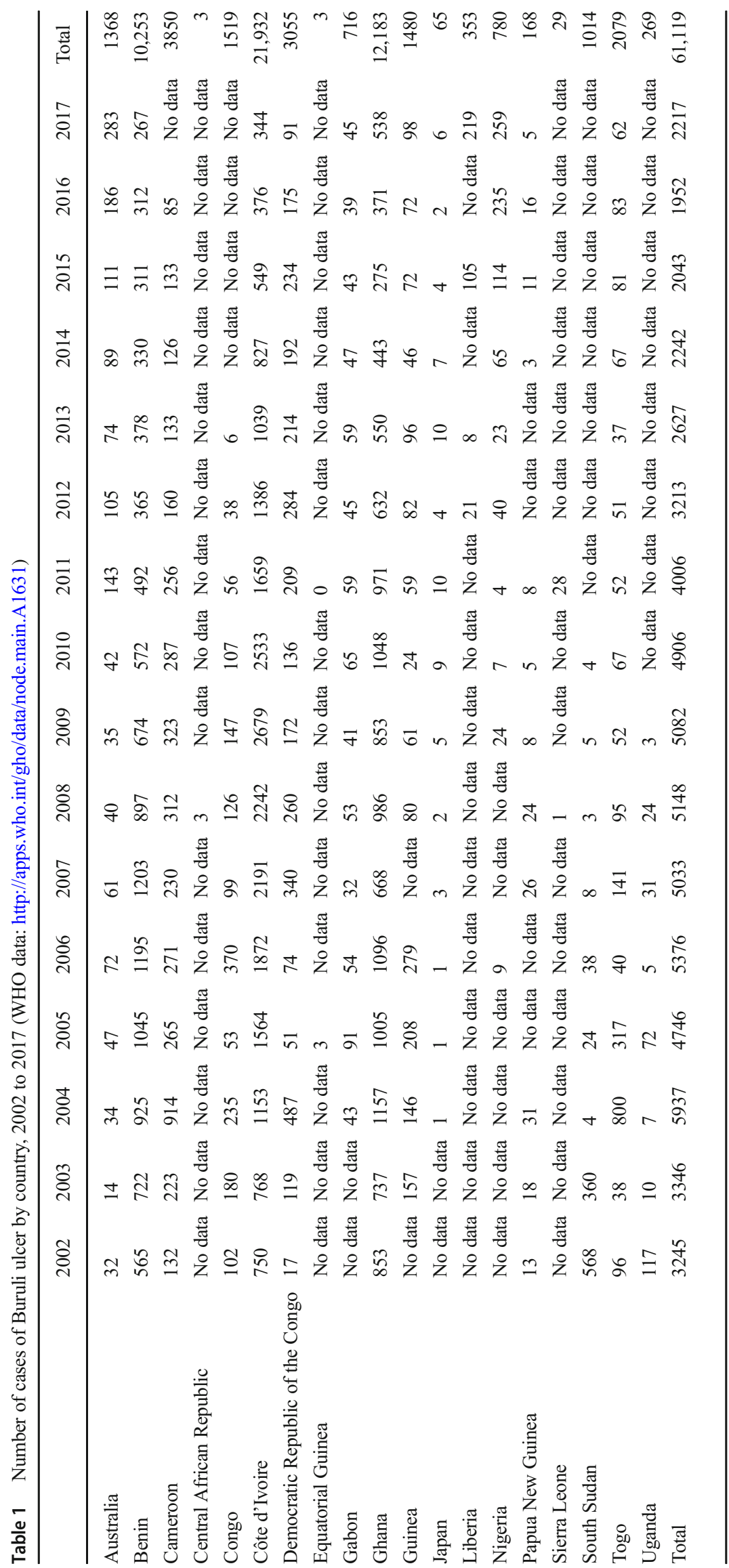




\section{Uncovering the Mode of Transmission}

The mode of transmission of BU remains poorly understood. As cases are concentrated in areas with proximity to slow moving or stagnant bodies of water (ponds, swamps, marshes, backwaters, dams, artificial lakes), the current hypothesis is that the disease is transmitted from these environments to humans [12]. This is further supported by the clinical presentation of the disease: the lesions are often distributed on the exposed areas of the body including the limbs and the face. There is no evidence to support the possibility of human-tohuman transmission of BU [13].

Investigation on potential reservoirs of M. ulcerans is ongoing. The slow growth rate of M. ulcerans (doubling time $>48 \mathrm{~h}$ ) coupled with its low density poses special difficulties in the recovery of the bacteria in culture from environmental samples. Ideal decontamination protocols capable of inhibiting all contaminating fast-growing bacteria and fungi existing with M. ulcerans is required $[12,14]$. However, an improved culture technique has recently been proposed that may overcome this [15]. Currently, real-time PCR targeting M. ulcerans-specific DNA sequences (the insertion sequences IS2404 and IS2406, and genes present on the mycolactoneencoding plasmid such as KR-B and ER) is the technique used most frequently in surveys of environmental specimens $[12$, 16]. Although the presence of DNA does not provide definite proof of the presence of living bacteria, identification of M. ulcerans DNA has been successful in environmental samples ranging from water filtrates, soil, biofilms, fish, frogs, snails, crayfish, insects, to other invertebrates [14, 17-31]. Reports of successful culture of live bacteria from environmental samples are much rarer but have been reported from samples of an aquatic insect (Hemiptera or water strider) as well as from moss and aulacode (greater cane rat) feces [14, $15,32]$.

Remarkably, evidence from West African countries and Australia suggest that the mode of transmission may be different in tropical and temperate climates. For instance, while there is some evidence for mosquitoes as a potential passive vector for M. ulcerans in Australia [18, 33-35], there is less consistent support from studies in Benin, which did not detect M. ulcerans DNA in mosquito species [36] whereas a study in Cameroon did [37]. A few experimental laboratory studies also failed to confirm the implication of mosquitoes as biological agents for the transmission of M. ulcerans $[38,39 \bullet]$. In a study by Djouaka et al., ingestion of M. ulcerans was observed during the larvae stage of the mosquitoes but not during both pupae and adult stages, revealing the low ability of infected or colonized mosquitoes to vertically transmit $M$. ulcerans to their offspring [40]. Interestingly, a recent study by Wallace et al. demonstrated and proposed that a micro-puncture in the skin from any cause, whether from insect bites, injuries, or other natural means, has the potential to inject M. ulcerans from the environment into the skin and generate ulcers [39॰]. Such a mechanism would also be sufficient to explain the potential role of biting water insects such as Naucoridae and Belostomatidae [12], which have received a lot of attention as potential vectors in West African countries.

There may be several routes of transmission in $\mathrm{BU}$ as the disease occurs in a range of different epidemiological settings and geographic regions, as well as some role for various living organisms acting as reservoirs and as vectors.

\section{Risk Factors for Buruli Ulcer}

In addition to living in proximity of potentially contaminated water sources, other postulated risk factors for acquiring $\mathrm{BU}$ are related to aquatic environment; for instance, receiving insect bites near a river, swimming in or wading through a river, bathing with water from open borehole, and farming [33, 41-44]. Younger age ( $<15$ years), poor pre-existing wound care, and failure to wear protective clothing are other presumed risk factors, as well as lack of use of mosquito nets [43-45]. A study in Australia demonstrated the use of insect repellent was associated with reduced risk while reporting of mosquito bites was associated with increased risk [33]. Seasonality is also suspected, and some studies report the risk of acquiring the disease increases during the wet season [16]. However, not all infected persons manifest the disease, and spontaneous healing has been observed to occur [46-49].

Besides these socio-demographic, environmental, or behavioral factors, there may also be some genetic host susceptibility factors to BU. Some genetic host susceptibility factors are observed in other mycobacterial diseases including natural resistance-associated macrophage protein-1 (NRAMP-1), HLA-DR, vitamin $\mathrm{D}_{3}$ receptor, mannosebinding protein, interferon-gamma (IFN- $\Gamma$ ) receptor, tumor necrosis factor alpha (TNF-a), interleukin (IL)-1a and IL- $1 \beta$ and their receptor antagonists, and IL-12 [50]. A study in Benin revealed history of BU in a family member was associated with increased risk (OR, 5.5 (95\% CI, 3.0-10.0), $p<0.001$ ) [51]. A similar observation has been made in other studies. However, data on possible genetic host factors is still limited. One study from Ghana has shown a genetic polymorphism in the SLC11A1 gene to play a role in susceptibility to develop BU, with an estimated $13 \%$ population attributable risk [52]. Currently, preventative measures for BU are not exactly known and a better understanding of these genetic risk factors may enable the development of effective and efficient measures in the future. 


\section{Pathogenesis-More Discoveries in Mycolactone}

Pathogenesis of BU relies on mycolactone, a polyketidederived macrolide that is synthesized by the M. ulcerans bacteria [53]. It is synthesized by giant polyketide synthetases coded in a 174-kb plasmid pMUM001, with possible involvement of other genes on the bacterial chromosome [53, 54]. Three major biological functions of mycolactone have been identified including cytotoxicity, immunosuppression, and analgesic effects, which correspond well to the characteristic features of the disease, i.e., extensive deep ulceration with thick yellowish necrotic tissue and undermining, paucity of local inflammatory response, and no or limited pain.

It is now widely accepted that the major cellular target of mycolactone is the Sec61 translocon [55]. This molecular machine sits at the interface between the cytosol and the endoplasmic reticulum (ER) and is essential for the translocation of around $30-50 \%$ of proteins that must cross this membrane. Such proteins are involved in vital processes that drive cellcell communication such as the immune response. Hence, Sec61-dependent loss of cytokines [56, 57], cellular receptors [57], and antigen presentation molecules [58] has now been shown to underpin the immunosuppression seen in the disease.

Inhibition of Sec61 also explains mycolactone's cellular toxicity. Single amino acid substitutions in the Sec61Al gene (encoding the $\alpha$ subunit of the translocon) have been shown to confer resistance to the cytotoxic effects of mycolactone [57]. Furthermore, an unbiased screen for resistance mutations in the human genome identified Sec61A1 substitutions alone. Recently, the molecular mechanism linking this to cell death was shown to involve the mislocalisation of Sec61 substrates into the cytosol [56], leading to uncontrolled cellular stress and $\mathrm{Bim} / \mathrm{Bcl} 2$-mediated apopotosis [59].

Mycolactone has also been shown to inhibit mTOR activity [60], and causes hyper-activation of WASP, members of a family of scaffold proteins transducing variety of signals into dynamic remodeling of the cell's actin cytoskeleton [61]. Furthermore, it activates type 2 angiotensin II receptors, resulting in hypoesthesia through potassium-dependent hyperpolarization of neurons. This may explain the painlessness or minimal pain associated with BU lesions [62], yet other studies suggest that other functions, including potential cytotoxity effect against the Schwann cells, account for this phenomenon [63]. It is not surprising that several pathways are present, making mycolactone a multifunctional cytotoxin given the pathological features of BU. Mycolactone is indeed an interesting molecule, and further understanding of its function may extend beyond understanding of BU pathogenesis.

It is important to note that mycolactone production is not limited to M. ulcerans. Indeed, there is a whole family of mycolactone-producing mycobacteria (MPM) including certain strains of M. marinum, M. pseudoshottsii, M. liflandii, and
M. xenopi $[64,65]$. Slight differences in the modular arrangement of genes on pMUM001 mean that they each produce different congeners of mycolactone [55].

\section{Diagnosis-New Diagnostic Tools?}

Currently, BU diagnostic confirmation is done through detection of M. ulcerans DNA using PCR of IS2404, IS2606, and ER. Other methods for confirmation of BU include microscopic detection of acid-fast bacilli in lesions, cultures, and histopathology. WHO target is for over $70 \%$ of reported cases to be PCR confirmed [6]. However, many of the endemic areas do not have an easy access to facilities to conduct these tests and thus case confirmation continues to be a challenge.

New diagnostic tools are currently under development not only for early detection of cases, especially ones that could be used at field level, but also for case management. These include the loop-mediated isothermal amplification (LAMP) test $[66,67]$, thin-layer chromatography for the detection of mycolactone [68], and antigen detection assays [69]. Field applicable formats of these tests are under development to provide rapid and sensitive diagnostic tests close to $\mathrm{BU}$ patients.

In the absence of a point-of-care diagnostic test, clinical diagnosis can be made in endemic areas with some degree of reliability given the distinctive clinical features of this disease. A recent study by Eddyani et al. reported that attending clinicians' diagnosis of BU had a high sensitivity of $92 \%$ (95\% CI, 85-96\%) compared against the reference diagnosis made by the expert panel in Benin [70]. Nonetheless, there is a wide range of differential diagnoses of skin ulcers, and more understanding of the disease distribution encountered in $\mathrm{BU}$ hospitals/clinics of endemic regions is necessary [70-72]. The accelerating development of technology and communication networks, the use of teledermatology and artificial intelligence, in the future, may enhance diagnosis of $\mathrm{BU}$ and other skin ulcers in the field $[1,2,73]$.

\section{Treatment with No Injection}

In 2004, based on in vitro findings and pilot-clinical studies, the WHO recommended a combination of rifampicin $(10 \mathrm{mg} / \mathrm{kg}$ orally once daily) and streptomycin $(15 \mathrm{mg} / \mathrm{kg}$ intramuscularly once daily) for 8 weeks as the first-line therapy for BU [74]. Before this time, surgery was the core treatment, believed to be the most effective, but it was associated with prolonged hospitalization, high cost, and high recurrence rate (6-21.5\%) [75-78]. Introduction of this antibiotic treatment has substantially changed the management and led to better outcomes. Cure was achieved at a much higher rate, and fewer patients needed amputation [79]. 
However, not only is streptomycin injection associated with significant nephrotoxicity and ototoxicity, it required daily visits to healthcare centers or hospitalization, depriving patients time and opportunities to conduct their daily activities. The impact could be more pronounced in children - the most affected population - affecting their education. This also affected early case detection as this created fear among patients and families and prevented them from seeking care at healthcare facilities [80].

Currently, all oral antibiotic therapy for BU is being investigated [81]. Data from a randomized control trial and several systemic case series studies [82-84], suggest that an all-oral antibiotic combination of rifampicin and clarithromycin (7.5 $\mathrm{mg} / \mathrm{kg}$ twice daily) would be effective [6]. Other rifampicin-based combinations are also being studied, for example, rifampicin plus ciprofloxacin, clarithroymycin, moxifoxacin, ethambutol, amikacin, or azithromycin in Australia $[85,86]$ and rifampicin, clarithromycin, plus levofloxacin in Japan [87]. Besides antibiotic types, we may also need to revisit the dosage and treatment duration, which have largely been decided on the basis of experience and therefore lack in evidence [81].

Paradoxical reaction is the worsening of symptoms during effective antibiotic treatment, which is another characteristic feature of BU. This is due to a recovered host inflammatory response to M. ulcerans and to the dying bacteria with fall in the mycolactone levels [88]. This phenomenon is reported to occur at the rate of between 1.9 and $26 \%$ [83, 85, 86, 89-91] and has previously been mistaken for recurrence or relapse in some cases. Paradoxical reactions might also have led to unnecessary surgical interventions due to mistakenly perceived treatment failure. Recently, a randomized controlled trial in Benin investigated the possible effects of delaying the decision to operate at 14 weeks rather than at standard 8 weeks would have any effect [92•]. Their results showed that delaying the decision to operate led to decreased rate of surgery and reduced median time of hospitalization and wound care, without any effect on occurrence of functional impairment [92•]. This provides a new insight into the treatment of $\mathrm{BU}$, that we may have been misinterpreting the need of surgical intervention at an inappropriate time-point when paradoxical reaction is likely to happen. On the other hand, we also need to appreciate the benefits of surgery that it may have on severe cases. More assessment and development of guidelines, algorithms, or training materials are needed to facilitate the surgical interventions in BU for better outcomes.

\section{Importance of Wound Management in Buruli Ulcer}

Wound management is an important pillar in the treatment of BU but often goes neglected. Ulcers can take months and years to heal, even after successful treatment with antibiotics under inadequate care. Large scars and contractures leading to functional impairment may further happen due to prolonged ulceration [93, 94]. Nonetheless, there are a number of challenges in settings where the disease is endemic to achieve a high standard of wound management from hygiene to availability of materials.

Good wound management is required not only for faster and sequelae-free epithelialization of ulcers but also for increased quality of life of patients. BU lesions were previously noticed to be associated with no or limited pain, but recent studies have revealed that many patients actually experience pain after the start of treatment $[72,95,96]$. This pain is most felt during wound dressing change when in many settings, gauze is the only dressing type being used [97]. Gauze is inexpensive and readily available, but the disadvantages are that it adheres to the wound bed not only causing pain during dressing change, but also may impair the dermal regeneration.

There has been an extensive development in wound management techniques and materials in recent years as the market is growing with the increase in number of patients with skin ulcers from non-infectious causes, e.g., diabetes and peripheral arterial diseases, in developed countries. Although cost may be an issue in using them, they may result in shortening the wound healing time, ultimately contributing to cost reduction. Some innovative approaches have been piloted for management of BU wounds, including use of absorbent form dressing HydroTac $^{\circledR}$ (Harmann, Heidenheim, Germany) and negativepressure wound therapy V.A.C. Therapy System ${ }^{\circledR}$ (Kinetics Concepts Inc. (KCI), San Antonio, USA) with successful outcomes $[98,99]$. More of these experiences are needed to be accumulated, together with cost analysis, to address the longterm benefit of such treatments. Development of similar, more field-friendly wound management techniques and materials with reduced cost are anticipated. In addition, as standards of wound management are heterogeneous between healthcare providers and between institutions [97], development of training materials and courses are also another needed intervention.

\section{Prevention}

Some prevention against BU has been observed with Mycobacterium bovis bacillus Calmette-Guérin (BCG) vaccination, but the results are controversial [100]. Vaccines specific to M. ulcerans, targeting a mycolyl transferase (antigen $85 \mathrm{~A}$ ) of the bacteria, are also being tested [101], but there is as yet no established definite measure for preventing the disease. At present, the only preventative measures that can be taken are to avoid risky behaviors (swimming, fishing, agricultural works, etc.) and environmental contacts in endemic areas. 


\section{Conclusions}

Introduction of antibiotic treatment in 2004, with rifampicin and streptomycin, has made a big change in management of BU and ultimately changed the lives of those affected. Since then, fewer patients need surgical interventions and amputations are no longer a common treatment option. The search for better and easier treatment options is in progress. Additionally, a better understanding of the mode of transmission of the disease and development of field-friendly rapid diagnostic tools are essential in order to enhance our fight against BU. Mycolactone is a unique toxin secreted by M. ulcerans which could also be a target substance in control of this disease. In recent years, the disease group of skin NTDs has been gaining more attention due to its potential for effective integration of their control. This current trend could bring about another big change in the control of this disabling disease.

Funding Sources This paper was supported by the following: (1) The Japan Agency for Medical Research and Development (AMED), Japan (grant number: 18jm0510004h0001) and (2) Grant-in-Aid for Scientific Research (KAKENHI), Japan (grant number: 16 K21656).

\section{Compliance with Ethical Standards}

Conflict of Interest Rie R. Yotsu, Koichi Suzuki, Rachel E Simmonds, Roger Bedimo, Anthony Ablordey, Dorothy Yeboah-Manu, Richard Phillips, and Kingsley Asiedu declare no conflict of interest.

Human and Animal Rights and Informed Consent This article does not contain any studies with human or animal subjects performed by any of the authors.

Open Access This article is distributed under the terms of the Creative Commons Attribution 4.0 International License (http:// creativecommons.org/licenses/by/4.0/), which permits unrestricted use, distribution, and reproduction in any medium, provided you give appropriate credit to the original author(s) and the source, provide a link to the Creative Commons license, and indicate if changes were made.

\section{References}

Papers of particular interest, published recently, have been highlighted as:

- Of importance

1. Mitjà $\mathrm{O}$, Marks M, Bertran L, Kollie K, Argaw D, Fahal AH, et al. Integrated control and management of neglected tropical skin diseases. PLoS Negl Trop Dis. 2017;11(1):e0005136 This position paper advocates and describes integration of skin-related neglected tropical diseases (skin NTDs), including, but not limited to, Buruli ulcer, leprosy, yaws, leishmaniasis, and mycteoma, which diseases are the neglected of the neglected.

2. Yotsu RR, Kouadio K, Vagamon B, N'Guessan K, Akpa AJ, Yao A, et al. Skin disease prevalence study in schoolchildren in rural Cote d'Ivoire: implications for integration of neglected skin diseases (skin NTDs). PLoS Negl Trop Dis. 2018;12:e006489. https://doi.org/10.1371/journal.pntd.0006489.

3. Fenner $F$. The significance of the incubation period in infectious diseases. Med J Aust. 1950;2:813-8.

4. Mac CP, Tolhurst JC, et al. A new mycobacterial infection in man. J Pathol Bacteriol. 1948;60:93-122.

5. Global Buruli Ulcer Initiative. Buruli ulcer. World Health Organization 2018. http://www.who.int/buruli/en/. Accessed 6 June 2018

6. Global Buruli Ulcer Initiative. Buruli ulcer (Mycobacterium ulcerans infection). Geneva, Switzerland: World Health Organization 2018. http://www.who.int/buruli/en/. Accessed 8 June 2018.

7. Tai AYC, Athan E, Friedman ND, Hughes A, Walton A, O'Brien DP. Increased severity and spread of Mycobacterium ulcerans, Southeastern Australia. Emerg Infect Dis. 2018;24:58-64. https://doi.org/10.3201/eid2401.171070.

8. Yotsu RR, Murase C, Sugawara M, Suzuki K, Nakanaga K, Ishii N, et al. Revisiting Buruli ulcer. J Dermatol. 2015;42:1033-41. https://doi.org/10.1111/1346-8138.13049.

9. Bar W, Rusch-Gerdes S, Richter E, Marquez de Bar G, Dittmer C, Papsdorf H, et al. Mycobacterium ulcerans infection in a child from Angola: diagnosis by direct detection and culture. Tropical Med Int Health. 1998;3:189-96.

10. Thomas BS, Bailey TC, Bhatnagar J, Ritter JM, Emery BD, Jassim OW, et al. Mycobacterium ulcerans infection imported from Australia to Missouri, USA, 2012. Emerg Infect Dis. 2014;20:1876-9. https://doi.org/10.3201/eid2011.131534.

11. Faber WR, Arias-Bouda LM, Zeegelaar JE, Kolk AH, Fonteyne PA, Toonstra J, et al. First reported case of Mycobacterium ulcerans infection in a patient from China. Trans R Soc Trop Med Hyg. 2000;94:277-9.

12. Merritt RW, Walker ED, Small PL, Wallace JR, Johnson PD, Benbow ME, et al. Ecology and transmission of Buruli ulcer disease: a systematic review. PLoS Negl Trop Dis. 2010;4:e911. https://doi.org/10.1371/journal.pntd.0000911.

13. Uganda-Buruli-Group. Epidemiology of Mycobacterium ulcerans infection (Buruli ulcer) at Kinyara, Uganda. Trans R Soc Trop Med Hyg. 1971;65:763-75.

14. Portaels F, Meyers WM, Ablordey A, Castro AG, Chemlal K, de Rijk P, et al. First cultivation and characterization of Mycobacterium ulcerans from the environment. PLoS Negl Trop Dis. 2008;2:e178. https://doi.org/10.1371/journal.pntd.0000178.

15. Zingue D, Panda A, Drancourt M. A protocol for culturing environmental strains of the Buruli ulcer agent, Mycobacterium ulcerans. Sci Rep. 2018;8:6778. https://doi.org/10.1038/s41598018-25278-y.

16. Aboagye S, Ampah K, Ross A, Asare P, Otchere I, Fyfe J, et al. Seasonal pattern of Mycobacterium ulcerans, the causative agent of Buruli ulcer, in the environment in Ghana. Microb Ecol. 2017;74:350-61.

17. Portaels F, Chemlal K, Elsen P, Johnson PD, Hayman JA, Hibble $\mathrm{J}$, et al. Mycobacterium ulcerans in wild animals. Rev Sci Tech. 2001;20:252-64.

18. Johnson PD, Azuolas J, Lavender CJ, Wishart E, Stinear TP, Hayman JA, et al. Mycobacterium ulcerans in mosquitoes captured during outbreak of Buruli ulcer, southeastern Australia. Emerg Infect Dis. 2007;13:1653-60. https://doi.org/10.3201/ eid1311.061369.

19. Marsollier L, Severin T, Aubry J, Merritt RW, Saint Andre JP, Legras P, et al. Aquatic snails, passive hosts of Mycobacterium ulcerans. Appl Environ Microbiol. 2004;70:6296-8. https://doi. org/10.1128/AEM.70.10.6296-6298.2004.

20. Marsollier L, Stinear T, Aubry J, Saint Andre JP, Robert R, Legras $\mathrm{P}$, et al. Aquatic plants stimulate the growth of and biofilm formation by Mycobacterium ulcerans in axenic culture and harbor 
these bacteria in the environment. Appl Environ Microbiol. 2004;70:1097-103.

21. Marsollier L, Robert R, Aubry J, Saint Andre JP, Kouakou H, Legras P, et al. Aquatic insects as a vector for Mycobacterium ulcerans. Appl Environ Microbiol. 2002;68:4623-8.

22. Williamson HR, Benbow ME, Nguyen KD, Beachboard DC, Kimbirauskas RK, McIntosh MD, et al. Distribution of Mycobacterium ulcerans in buruli ulcer endemic and nonendemic aquatic sites in Ghana. PLoS Negl Trop Dis. 2008;2: e205. https://doi.org/10.1371/journal.pntd.0000205.

23. Eddyani M, Ofori-Adjei D, Teugels G, De Weirdt D, Boakye D, Meyers WM, et al. Potential role for fish in transmission of Mycobacterium ulcerans disease (Buruli ulcer): an environmental study. Appl Environ Microbiol. 2004;70:5679-81. https://doi.org/ 10.1128/AEM.70.9.5679-5681.2004.

24. Portaels F, Elsen P, Guimaraes-Peres A, Fonteyne PA, Meyers WM. Insects in the transmission of Mycobacterium ulcerans infection. Lancet. 1999;353:986. https://doi.org/10.1016/S01406736(98)05177-0.

25. Stinear T, Davies JK, Jenkin GA, Hayman JA, Oppedisano F, Johnson PD. Identification of Mycobacterium ulcerans in the environment from regions in Southeast Australia in which it is endemic with sequence capture-PCR. Appl Environ Microbiol. 2000;66:3206-13.

26. Kotlowski R, Martin A, Ablordey A, Chemlal K, Fonteyne PA, Portaels F. One-tube cell lysis and DNA extraction procedure for PCR-based detection of Mycobacterium ulcerans in aquatic insects, molluscs and fish. J Med Microbiol. 2004;53:927-33. https://doi.org/10.1099/jmm.0.45593-0.

27. Fyfe JA, Lavender CJ, Johnson PD, Globan M, Sievers A, Azuolas J, et al. Development and application of two multiplex real-time PCR assays for the detection of Mycobacterium ulcerans in clinical and environmental samples. Appl Environ Microbiol. 2007;73:4733-40. https://doi.org/10.1128/AEM.02971-06.

28. Trott KA, Stacy BA, Lifland BD, Diggs HE, Harland RM, Khokha MK, et al. Characterization of a Mycobacterium ulcerans-like infection in a colony of African tropical clawed frogs (Xenopus tropicalis). Comp Med. 2004;54:309-17.

29. Tian RB, Niamke S, Tissot-Dupont H, Drancourt M. Detection of Mycobacterium ulcerans DNA in the environment, Ivory Coast. PLoS One. 2016;11:e0151567. https://doi.org/10.1371/journal. pone. 0151567.

30. Luo Y, Degang Y, Ohtsuka M, Ishido Y, Ishii N, Suzuki K. Detection of Mycobacterium ulcerans subsp. shinshuense DNA from a water channel in familial Buruli ulcer cases in Japan. Future Microbiol. 2015;10:461-9. https://doi.org/10.2217/fmb. 14.152 .

31. Maman I, Tchacondo T, Kere AB, Beissner M, Badziklou K, Tedihou E, et al. Molecular detection of Mycobacterium ulcerans in the environment and its relationship with Buruli ulcer occurrence in Zio and Yoto districts of maritime region in Togo. PLoS Negl Trop Dis. 2018;12:e0006455. https://doi.org/10.1371/ journal.pntd.0006455.

32. Kpeli G, Darko Otchere I, Lamelas A, Buultjens AL, Bulach D, Baines SL, et al. Possible healthcare-associated transmission as a cause of secondary infection and population structure of Staphylococcus aureus isolates from two wound treatment centres in Ghana. New Microbes New Infect. 2016;13:92-101.

33. Quek TY, Athan E, Henry MJ, Pasco JA, Redden-Hoare J, Hughes A, et al. Risk factors for Mycobacterium ulcerans infection, southeastern Australia. Emerg Infect Dis. 2007;13:1661-6. https://doi. org/10.3201/eid1311.061206.

34. Lavender CJ, Fyfe JA, Azuolas J, Brown K, Evans RN, Ray LR, et al. Risk of Buruli ulcer and detection of Mycobacterium ulcerans in mosquitoes in southeastern Australia. PLoS Negl
Trop Dis. 2011;5:e1305. https://doi.org/10.1371/journal.pntd. 0001305.

35. Johnson PD, Lavender CJ. Correlation between Buruli ulcer and vector-borne notifiable diseases, Victoria, Australia. Emerg Infect Dis. 2009;15:614-5. https://doi.org/10.3201/eid1504.081162.

36. Zogo B, Djenontin A, Carolan K, Babonneau J, Guegan JF, Eyangoh S, et al. A field study in Benin to investigate the role of mosquitoes and other flying insects in the ecology of Mycobacterium ulcerans. PLoS Neg1 Trop Dis. 2015;9: e0003941. https://doi.org/10.1371/journal.pntd.0003941.

37. Gall PL LJ, Ndengue DM, et al., Detection of Mycobacterium ulcerans in domestic arthropods in a Buruli ulcer endemic site, Akonolinga, Cameroon. WHO Buruli Ulcer Meeting: Geneva, World Health Organization; 2015.

38. Wallace JR, Gordon MC, Hartsell L, Mosi L, Benbow ME, Merritt $\mathrm{RW}$, et al. Interaction of Mycobacterium ulcerans with mosquito species: implications for transmission and trophic relationships. Appl Environ Microbiol. 2010;76:6215-22. https://doi.org/10. 1128/AEM.00340-10.

39. Wallace J, Mangas K, Porter J, Marcsisin R, Pidot S, Howden B, et al. Mycobacterium ulcerans low infectious dose and mechanical transmission support insect bites and puncturing injuries in the spread of Buruli ulcer. PLoS Negl Trop Dis. 2017;11(4): e0005553-e. This study reports on a new insight into how Buruli ulcer may be transmitted.

40. Djouaka R, Zeukeng F, Daiga Bigoga J, N'Golo Coulibaly D, Tchigossou G, Akoton R, et al. Mycobacterium ulcerans. Can J Infect Dis Med Microbiol. 2017;2017:1324310.

41. Jacobsen KH, Padgett JJ. Risk factors for Mycobacterium ulcerans infection. Int J Infect Dis. 2010;14:e677-81. https:// doi.org/10.1016/j.ijid.2009.11.013.

42. Aiga H, Amano T, Cairncross S, Adomako J, Nanas OK, Coleman $\mathrm{S}$. Assessing water-related risk factors for Buruli ulcer: a casecontrol study in Ghana. Am J Trop Med Hyg. 2004;71:387-92.

43. Raghunathan PL, Whitney EA, Asamoa K, Stienstra Y, Taylor TH $\mathrm{Jr}$, Amofah GK, et al. Risk factors for Buruli ulcer disease (Mycobacterium ulcerans infection): results from a case-control study in Ghana. Clin Infect Dis. 2005;40:1445-53. https://doi.org/ $10.1086 / 429623$.

44. Maman I, Tchacondo T, Kere AB, Piten E, Beissner M, Kobara Y, et al. Risk factors for Mycobacterium ulcerans infection (Buruli ulcer) in Togo horizontal line a case-control study in Zio and Yoto districts of the maritime region. BMC Infect Dis. 2018;18:48. https://doi.org/10.1186/s12879-018-2958-3.

45. Debacker M, Aguiar J, Steunou C, Zinsou C, Meyers WM, Scott JT, et al. Mycobacterium ulcerans disease: role of age and gender in incidence and morbidity. Tropical Med Int Health. 2004;9: 1297-304. https://doi.org/10.1111/j.1365-3156.2004.01339.x.

46. Gordon CL, Buntine JA, Hayman JA, Lavender CJ, Fyfe JA, Hosking P, et al. Spontaneous clearance of Mycobacterium ulcerans in a case of Buruli ulcer. PLoS Negl Trop Dis. 2011;5: e1290. https://doi.org/10.1371/journal.pntd.0001290.

47. Connor D, Lunn H. Buruli ulceration - a clinicopathologic study of 38 Ugandans with Mycobacterium ulcerans ulceration. Arch Pathol. 1966;81:17.

48. Revill WD, Morrow RH, Pike MC, Ateng J. A controlled trial of the treatment of Mycobacterium ulcerans infection with clofazimine. Lancet. 1973;2:873-7.

49. Marion E, Chauty A, Kempf M, Le Corre Y, Delneste Y, Croue A, et al. Clinical features of spontaneous partial healing during Mycobacterium ulcerans infection. Open Forum Infect Dis. 2016;3:ofw013.

50. Stienstra Y, van der Graaf WT, te Meerman GJ, The TH, de Leij LF, van der Werf TS. Susceptibility to development of Mycobacterium ulcerans disease: review of possible risk factors. Tropical Med Int Health. 2001;6:554-62. 
51. Sopoh GE, Barogui YT, Johnson RC, Dossou AD, Makoutode M, Anagonou SY, et al. Family relationship, water contact and occurrence of Buruli ulcer in Benin. PLoS Negl Trop Dis. 2010;4:e746. https://doi.org/10.1371/journal.pntd.0000746.

52. Stienstra Y, van der Werf TS, Oosterom E, Nolte IM, van der Graaf WT, Etuaful S, et al. Susceptibility to Buruli ulcer is associated with the SLC11A1 (NRAMP1) D543N polymorphism. Genes Immun. 2006;7:185-9. https://doi.org/10.1038/sj.gene. 6364281.

53. George KM, Chatterjee D, Gunawardana G, Welty D, Hayman J, Lee R, et al. Mycolactone: a polyketide toxin from Mycobacterium ulcerans required for virulence. Science. 1999;283:854-7.

54. Stinear TP, Pryor MJ, Porter JL, Cole ST. Functional analysis and annotation of the virulence plasmid pMUM001 from Mycobacterium ulcerans. Microbiology. 2005;151:683-92. https://doi.org/10.1099/mic.0.27674-0.

55. Sarfo FS, Phillips R, Wansbrough-Jones M, Simmonds RE. Recent advances: role of mycolactone in the pathogenesis and monitoring of Mycobacterium ulcerans infection/Buruli ulcer disease. Cell Microbiol. 2016;18:17-29. https://doi.org/10.1111/cmi. 12547.

56. Hall BS, Hill K, McKenna M, Ogbechi J, High S, Willis AE, et al. The pathogenic mechanism of the Mycobacterium ulcerans virulence factor, mycolactone, depends on blockade of protein translocation into the ER. PLoS Pathog. 2014;10:e1004061. https://doi. org/10.1371/journal.ppat.1004061.

57. Baron L, Paatero AO, Morel JD, Impens F, Guenin-Mace L, SaintAuret S, et al. Mycolactone subverts immunity by selectively blocking the Sec61 translocon. J Exp Med. 2016;213:2885-96. https://doi.org/10.1084/jem.20160662.

58. Grotzke JE, Kozik P, Morel JD, Impens F, Pietrosemoli N, Cresswell P, et al. Sec61 blockade by mycolactone inhibits antigen cross-presentation independently of endosome-to-cytosol export. Proc Natl Acad Sci U S A. 2017;114:E5910-E9. https://doi.org/ 10.1073/pnas.1705242114.

59. Ogbechi J, Hall BS, Sbarrato T, Taunton J, Willis AE, Wek RC, et al. Inhibition of Sec61-dependent translocation by mycolactone uncouples the integrated stress response from ER stress, driving cytotoxicity via translational activation of ATF4. Cell Death Dis. 2018;9:397. https://doi.org/10.1038/s41419-018-0427-y.

60. Bieri R, Scherr N, Ruf MT, Dangy JP, Gersbach P, Gehringer M, et al. The macrolide toxin Mycolactone promotes Bim-dependent apoptosis in Buruli ulcer through inhibition of mTOR. ACS Chem Biol. 2017;12:1297-307. https://doi.org/10.1021/acschembio. $7 \mathrm{~b} 00053$.

61. Guenin-Mace L, Veyron-Churlet R, Thoulouze MI, RometLemonne G, Hong H, Leadlay PF, et al. Mycolactone activation of Wiskott-Aldrich syndrome proteins underpins Buruli ulcer formation. J Clin Invest. 2013;123:1501-12. https://doi.org/10.1172/ JCI66576.

62. Marion E, Song OR, Christophe T, Babonneau J, Fenistein D, Eyer J, et al. Mycobacterial toxin induces analgesia in buruli ulcer by targeting the angiotensin pathways. Cell. 2014;157:1565-76. https://doi.org/10.1016/j.cell.2014.04.040.

63. En J, Kitamoto S, Kawashima A, Yonezawa S, Kishi Y, Ishii N, et al. Mycolactone cytotoxicity in Schwann cells could explain nerve damage in Buruli ulcer. PLoS Negl Trop Dis. 2017;11: e0005834. https://doi.org/10.1371/journal.pntd.0005834.

64. Yip MJ, Porter JL, Fyfe JA, Lavender CJ, Portaels F, Rhodes M, et al. Evolution of Mycobacterium ulcerans and other mycolactone-producing mycobacteria from a common Mycobacterium marinum progenitor. J Bacteriol. 2007;189: 2021-9. https://doi.org/10.1128/JB.01442-06.

65. Narh CA, Mosi L, Quaye C, Tay SC, Bonfoh B, de Souza DK. Genotyping tools for Mycobacterium ulcerans-drawbacks and future prospects. Mycobact Dis. 2014;4:1000149. https://doi.org/ 10.4172/2161-1068.1000149.

66. Ablordey A, Amissah DA, Aboagye IF, Hatano B, Yamazaki T, Sata T, et al. Detection of Mycobacterium ulcerans by the loop mediated isothermal amplification method. PLoS Negl Trop Dis. 2012;6:e1590. https://doi.org/10.1371/journal.pntd.0001590.

67. Beissner M, Phillips RO, Battke F, Bauer M, Badziklou K, Sarfo FS, et al. Loop-mediated isothermal amplification for laboratory confirmation of Buruli ulcer disease-towards a point-of-care test. PLoS Neg1 Trop Dis. 2015;9:e0004219. https://doi.org/10.1371/ journal.pntd.0004219.

68. Wadagni A, Frimpong M, Phanzu DM, Ablordey A, Kacou E, Gbedevi M, et al. Simple, rapid Mycobacterium ulcerans disease diagnosis from clinical samples by fluorescence of mycolactone on thin layer chromatography. PLoS Negl Trop Dis. 2015;9: e0004247. https://doi.org/10.1371/journal.pntd.0004247.

69. Dreyer A, Roltgen K, Dangy JP, Ruf MT, Scherr N, Bolz M, et al. Identification of the Mycobacterium ulcerans protein MUL_3720 as a promising target for the development of a diagnostic test for Buruli ulcer. PLoS Negl Trop Dis. 2015;9:e0003477. https://doi. org/10.1371/journal.pntd.0003477.

70. Eddyani M, Sopoh GE, Ayelo G, Brun LVC, Roux JJ, Barogui Y, et al. Diagnostic accuracy of clinical and microbiological signs in patients with skin lesions resembling Buruli ulcer in an endemic region. Clin Infect Dis. 2018;67:827-34. https://doi.org/10.1093/ cid/ciy197.

71. Toutous Trellu L, Nkemenang P, Comte E, Ehounou G, Atangana $\mathrm{P}$, Mboua D, et al. Differential diagnosis of skin ulcers in a Mycobacterium ulcerans endemic area: data from a prospective study in Cameroon. PLoS Negl Trop Dis. 2016;10:e0004385-e.

72. Addison NO, Pfau S, Koka E, Aboagye SY, Kpeli G, Pluschke G, et al. Assessing and managing wounds of Buruli ulcer patients at the primary and secondary health care levels in Ghana. PLoS Negl Trop Dis. 2017;11:e0005331. https://doi.org/10.1371/journal. pntd.0005331.

73. Navarrete-Dechent C, Dusza SW, Liopyris K, Marghoob AA, Halpern AC, Marchetti MA. Automated dermatological diagnosis: hype or reality? J Investig Dermatol. 2018. https://doi.org/10. 1016/j.jid.2018.04.040.

74. Global Buruli Ulcer Initiative. Provisional guidance on the role of specific antibiotics in the management of Mycobacterium ulcerans disease (Buruli ulcer): guidance for health workers. Geneva: WHO; 2004.

75. Asiedu K, Etuaful S. Socioeconomic implications of Buruli ulcer in Ghana: a three-year review. Am J Trop Med Hyg. 1998;59: 1015-22.

76. Debacker M, Aguiar J, Steunou C, Zinsou C, Meyers WM, Portaels F. Buruli ulcer recurrence, Benin. Emerg Infect Dis. 2005;11:584-9. https://doi.org/10.3201/eid1104.041000.

77. Kanga JM, Kacou DE, Sangare A, Dabila Y, Asse NH, Djakeaux S. Recurrence after surgical treatment of Buruli ulcer in Cote d'Ivoire. Bull Soc Pathol Exot. 2003;96:406-9.

78. Kibadi K, Mputu-Yamba JB, Mokassa B, Panda M, MuyembeTamfum JJ. Relapse after surgical treatment of mycobacterium ulcerans infection (buruli ulcer): study of risk factors in 84 patients in the Democratic Republic of the Congo. Med Trop (Mars). 2009;69:471-4.

79. Yotsu RR, Richardson M, Ishii N. Drugs for treating Buruli ulcer (Mycobacterium ulcerans disease) (review). Cochrane Database of Systematic Reviews. 2018;(8 Art. No.: CD012118). https://doi. org/10.1002/14651858.CD012118.pub2.

80. Ackumey MM, Gyapong M, Pappoe M, Maclean CK, Weiss MG. Socio-cultural determinants of timely and delayed treatment of Buruli ulcer: implications for disease control. Infect Dis Poverty. 2012;1:6. https://doi.org/10.1186/2049-9957-1-6. 
81. Yotsu RR, Richardson M, Ishii N. Drugs for treating Buruli ulcer (Mycobacterium ulcerans disease) (Review). Cochrane Database of Systematic Reviews 2018: Issue 8 Art. No.: CD012118. https:// doi.org/10.1002/14651858.CD012118.pub2.

82. Nienhuis WA, Stienstra Y, Thompson WA, Awuah PC, Abass $\mathrm{KM}$, Tuah W, et al. Antimicrobial treatment for early, limited Mycobacterium ulcerans infection: a randomised controlled trial. Lancet. 2010;375:664-72. https://doi.org/10.1016/S01406736(09)61962-0.

83. Phillips RO, Sarfo FS, Abass MK, Abotsi J, Wilson T, Forson M, et al. Clinical and bacteriological efficacy of rifampinstreptomycin combination for two weeks followed by rifampin and clarithromycin for six weeks for treatment of Mycobacterium ulcerans disease. Antimicrob Agents Chemother. 2014;58:1161-6. https://doi.org/10.1128/AAC. 02165-13.

84. Chauty A, Ardant MF, Marsollier L, Pluschke G, Landier J, Adeye A, et al. Oral treatment for Mycobacterium ulcerans infection: results from a pilot study in Benin. Clin Infect Dis. 2011;52:94 6. https://doi.org/10.1093/cid/ciq072.

85. O'Brien DP, McDonald A, Callan P, Robson M, Friedman ND, Hughes A, et al. Successful outcomes with oral fluoroquinolones combined with rifampicin in the treatment of Mycobacterium ulcerans: an observational cohort study. PLoS Negl Trop Dis. 2012;6:e1473. https://doi.org/10.1371/journal.pntd.0001473.

86. Friedman ND, Athan E, Walton AL, O'Brien DP. Increasing experience with primary Oral medical therapy for Mycobacterium ulcerans disease in an Australian cohort. Antimicrob Agents Chemother. 2016;60:2692-5. https://doi.org/10.1128/AAC. 02853-15.

87. Sugawara M, Ishii N, Nakanaga K, Suzuki K, Umebayashi Y, Makigami K, et al. Exploration of a standard treatment for Buruli ulcer through a comprehensive analysis of all cases diagnosed in Japan. J Dermatol. 2015;42:588-95. https://doi.org/10. 1111/1346-8138.12851.

88. O'Brien DP, Robson ME, Callan PP, McDonald AH. "Paradoxical" immune-mediated reactions to Mycobacterium ulcerans during antibiotic treatment: a result of treatment success, not failure. Med J Aust. 2009;191:564-6.

89. Sarfo FS, Phillips R, Asiedu K, Ampadu E, Bobi N, Adentwe E, et al. Clinical efficacy of combination of rifampin and streptomycin for treatment of Mycobacterium ulcerans disease. Antimicrob Agents Chemother. 2010;54:3678-85. https://doi.org/10.1128/ AAC.00299-10.

90. O’Brien DP, Robson M, Friedman ND, Walton A, McDonald A, Callan $\mathrm{P}$, et al. Incidence, clinical spectrum, diagnostic features, treatment and predictors of paradoxical reactions during antibiotic treatment of Mycobacterium ulcerans infections. BMC Infect Dis. 2013;13:416. https://doi.org/10.1186/1471-2334-13-416.
91. Barogui YT, Klis SA, Johnson RC, Phillips RO, van der Veer E, van Diemen C, et al. Genetic susceptibility and predictors of paradoxical reactions in Buruli ulcer. PLoS Negl Trop Dis. 2016;10: e0004594. https://doi.org/10.1371/journal.pntd.0004594.

92. Wadagni AC, Barogui YT, Johnson RC, Sopoh GE, Affolabi D, van der Werf TS, et al. Delayed versus standard assessment for excision surgery in patients with Buruli ulcer in Benin: a randomised controlled trial. The Lancet Infectious diseases. 2018;18(6):650-6. This study tested on the timing of surgery for ulcerated cases of Buruli ulcer in a randomized control study design. The findings make an important indication that decision to operate should be postponed later than the present practice at 8 weeks.

93. Barogui Y, Johnson RC, van der Werf TS, Sopoh G, Dossou A, Dijkstra PU, et al. Functional limitations after surgical or antibiotic treatment for Buruli ulcer in Benin. Am J Trop Med Hyg. 2009;81: $82-7$.

94. Stienstra Y, van Roest MH, van Wezel MJ, Wiersma IC, Hospers IC, Dijkstra PU, et al. Factors associated with functional limitations and subsequent employment or schooling in Buruli ulcer patients. Tropical Med Int Health. 2005;10:1251-7. https://doi. org/10.1111/j.1365-3156.2005.01519.x.

95. Velink A, Woolley RJ, Phillips RO, Abass KM, van der Werf TS, Agumah E, et al. Former Buruli ulcer patients' experiences and wishes may serve as a guide to further improve Buruli ulcer management. PLoS Negl Trop Dis. 2016;10:e0005261. https://doi.org/ 10.1371/journal.pntd.0005261.

96. Woolley RJ, Velink A, Phillips RO, Thompson WA, Abass KM, van der Werf TS, et al. Experiences of pain and expectations for its treatment among former Buruli ulcer patients. Am J Trop Med Hyg. 2016;95:1011-5. https://doi.org/10.4269/ajtmh.16-0419.

97. Velding K, Klis SA, Abass KM, Tuah W, Stienstra Y, van der Werf $\mathrm{T}$. Wound care in Buruli ulcer disease in Ghana and Benin. Am J Trop Med Hyg. 2014;91:313-8. https://doi.org/10.4269/ajtmh.130255 .

98. Velding K, Klis S-A, Abass KM, van der Werf TS, Stienstra Y. The application of modern dressings to Buruli ulcers: results from a pilot implementation project in Ghana. Am J Trop Med Hyg. 2016;95:60-2.

99. Murase C, Kono M, Nakanaga K, Ishii N, Akiyama M. Buruli ulcer successfully treated with negative-pressure wound therapy. JAMA Dermatol. 2015;151:1137-9. https://doi.org/10.1001/ jamadermatol.2015.1567.

100. Zimmermann P, Finn A, Curtis N. Does BCG Vaccination protect against non-tuberculous mycobacterial infection? A systematic review and meta-analysis. J Infect Dis 2018;218:679-87. https:// doi.org/10.1093/infdis/jiy207.

101. Guarner J. Buruli ulcer: review of a neglected skin mycobacterial disease. J Clin Microbiol. 2018;56. 